American Journal of Applied Sciences 4 (10): 774-778, 2007

ISSN 1546-9239

(C) 2007 Science Publications

\title{
The Influence of Consumers Behavior on the Variables Determining Residential Property Values in Lagos, Nigeria
}

\author{
M.O. Bello and V.A. Bello \\ Department of Estate Management, Federal University of Technology, Akure
}

\begin{abstract}
The objective of this study was to assess the influence of consumer behaviour on the variables determining residential property values in Lagos metropolis and how Nigerian valuers are incorporating these in their valuation exercise. The survey which was carried out within a period of three months (January, February and March 2006) involved buyers and valuers which participated in the sales of some properties within Lagos Metropolis. These buyers and valuers were asked to rank on a 4-point likert scale; the relative importance of each of the property attributes which affect the price of the property as perceived by them. The significance of each attribute was then assessed using Relative Importance Index (RII). The significant difference between the ranking of the buyers and valuers was assessed at each variable level and when all the variables were combined using the Kendall test of concordance and tested at .05 level of significant using chi- square approximation. Regressing the attributes of each property against the actual property paid, the significance of each attribute was determined; which was then compared with the ratings of both the valuers and the buyers. The study revealed that the methods of valuation used by the Nigerian estate surveyors and valuers do not take into consideration the buyers preferences in the assessments of residential property value.
\end{abstract}

Key words: Valuers, residential property value, relative importance index

\section{INTRODUCTION}

The fundamentals of property values are based upon collection, analysis and interpretation of value influencing variables. These variables are generally classified into two broad groups, namely those which are external and those that are internal to the property ${ }^{[1]}$. The former relates to the general state of the economy, population, employment, immigration, finance, location, transportation and neighborhood amenity while the later essentially constitutes the specific details of the property such as size, accommodation, condition, design, layout, age, type and plot size which can be both specified and measured ${ }^{[2]}$. The comparable method of valuation relies on the principle that the price a customer is willing to pay for a property depends on its attributes, that is:

$P=f\left(x_{i} y_{i}\right)$

Where

$\mathrm{P}=$ Price

$\mathrm{x}_{\mathrm{i}}=$ Specific attributes of the property e.g. No of room, plot area etc.

$\mathrm{y}_{\mathrm{i}}=$ External variables

In valuation parlance, external factors which are macro influences are believed to determine the general level of property values within an urban area. Unfortunately, their influences on value are difficult to assess using the conventional valuation method.

In practice, the analysis of these variables and their adjustment to sales price of the comparables are based on valuers' subjective judgment drawn from experience and knowledge of the local market. The skill of the valuers rests in the selection of comparable properties and recognition of key variables in order to arrive at value for the subject property, before; this has been regarded as a reliable and accurate method of valuing property ${ }^{[3]}$. However, researches within the last decades, have increasingly questioned the validity and accuracy of this method. This has been prompted by concerns relating to data quality; the number of comparables used and perceived subjectivity within the process $^{[4,5]}$.

Specifically, valuers have been criticized for having less than full understanding of how variables behave in contributing to the value of residential property ${ }^{[2]}$ and for not advancing knowledge on the significance of qualitative variables ${ }^{[4]}$. There is no consensus of opinion among researchers with regard to the specific influence of variables on value ${ }^{[2]}$, however; there seem to be unhelpful emphasis on supply related variables ${ }^{[6]}$. The flaw in few studies that have utilized both demand and supply variables ${ }^{[7]}$ evolved from the fact that demand has been identified using socioeconomic factors rather than identifying the influences recognized by consumer ${ }^{[6]}$.

Interestingly, much work has been done on the determinants of residential property values in developed countries, however in Nigeria, not much has been done in this area. The few that exist have only superficially addressed the issue ${ }^{[8,9]}$. This scenario brings us directly

Corresponding Author: $\quad$ M. O. Bello, Department of Estate Management, Federal University of Technology, Akure 
to two important issues. From Nigerian valuers perspective, how reasonable, defensible, logical and natural are their methods of determining values? How well do these methods interpret the Nigerian residential property market in terms of buyers' behaviors? These were the pertinent issues this study intends to address.

\section{MATERIALS AND METHODS}

In the review of the literature, one predominant method that was used in the assessment of buyers and valuers behaviors was the survey analysis ${ }^{[2]}$. In most cases, the data collection technique were similar, however, there were variations in the method of analysis. The general approach was the attempt to assess the significance or saliency of value influencing variables ${ }^{[10,1]}$. Since it is difficult to measure the significance of variables in absolute term, the mean score measure was usually employed. In each case, the variable with the highest mean score represented the most important variable ${ }^{[2]}$. This analysis based on mean score has been considered to be better than either the mode or median in ranking the relative influence of variable $^{[12]}$.

In contrast to mean score approach, one methodology that is worthy of notice is that adopted by Daly et al. ${ }^{[6]}$. Their study was based on qualitative analysis involving personal interview with residential consumer and practicing valuers in the United Kingdom; Ireland and Australia.

The different contextual and cultural settings as well as property market characteristics will obviously limit the direct application of these methodologies and their findings to Nigerian situation. In this wise, while the study adopted the survey analysis, the tools for data analysis employed were those that considered the peculiarity of Nigeria as a developing economy.

The survey which was carried out within period of three months (January, February and March 2006) involved the buyers and valuers which took part in the sales of some properties within Lagos Metropolis.

These buyers and valuers were asked to rank on a 4-point likert scale the relative importance of each of the property attributes which affect the price of the property as perceived by them. The significance of each attribute was then assessed using Relative Importance Index (RII).

$$
R I I=\frac{\sum a_{i} n_{i}}{\sum x_{j}}
$$

Where

$\mathrm{i}=$ response category index

$\mathrm{x}_{\mathrm{j}}=$ the sum of $\mathrm{j}$ factors $1,2,3 \ldots \ldots \ldots . \mathrm{N}$

$\mathrm{a}_{\mathrm{i}}=$ constant expressing the weight given to the ith response.

$\mathrm{n}_{\mathrm{i}}=$ the variable expressing the frequency of the ith resource.
Based on the RII score, each variable was ranked. The significant difference between the ranking of the buyers and valuers was assessed at each variable level and when all the variables were combined. Since, the samples of ranks are not continuous and their population can not be inferred to have the same distribution we considered the t-test and Mann-Whitney two sample test used by Adair et al. ${ }^{[2]}$ as not suitable ${ }^{[14]}$. Instead we adopted the Kendall test of concordance.

Regressing the attributes of each property against the actual property paid, the significance of each attribute was determined; which was then compared with the ratings of both the valuers and the buyers.

The form of Regression function used is

$\mathrm{P}=\mathrm{a}_{1}+\mathrm{b}_{1} \mathrm{X}_{1}+\mathrm{b}_{2} \mathrm{X}_{2}+\mathrm{b}_{3} \mathrm{X}_{3}=\ldots \ldots \ldots \ldots+\mathrm{b}_{\mathrm{n}} \mathrm{X}_{\mathrm{n}}$

Where $X_{i}=$ Residential property attributes

$b_{i}=$ Regression coefficients

\section{RESULTS AND DISCUSSION}

Table 1and 2 show the rankings of the salient variables by both the buyers and valuers for block of flats and duplex respectively.

The ranking was based on a 4-point relative importance Index scale (RII). The highest RII that is obtainable on this scale is 4 signifying that the variable is of very great importance; while the lowest is 1 indicating a variable that is of no importance. Similarly, the Kendall's coefficient of concordance W which was used to measure the level of agreement between the rankings of buyers and valuers ranges from 0.00 for no agreement to 1.0 for perfect agreement. From these Tables 1 and 2, three situations are discernible:

where the buyers and valuers are in perfect agreement, where there is no agreement between the buyers and valuers and where there is partial agreement between the buyers and valuers.

For block of flats (Table 1), the buyers and valuers are in perfect agreement that location, state of repairs and water supply are important determinants of residential property values while the presence of telephone network is of less importance. There was no agreement as to the influence exerted by variables such as nearness to place of work, availability of parking space and size of room. Variables such as electricity, number of bedroom and finishes reveal a partial but high level of agreement while security of neigbourhood, age of buildings, size of plot and number of toilets/baths are variables where the buyers and valuers have partial and low level of agreement.

The situation with respect to duplex is quiet different (Table 2). The only area where perfect agreement occurs is with variable "nearness to the place of work". Both buyers and valuers agree that this variable is of no importance. Other variables such as size of room, number of bedroom, state of repairs, 
Am. J. Applied Sci., 4 (10): 774-778, 2007

Table 1: Ranking of salient variables by buyers and valuers of block of flats

\begin{tabular}{|c|c|c|c|c|c|c|c|c|}
\hline \multirow[t]{4}{*}{ Variables } & \multicolumn{3}{|l|}{ Vluers ratings } & \multicolumn{3}{|l|}{ Buyers ratings } & \multirow[t]{4}{*}{$\mathrm{W}$} & \multirow[t]{4}{*}{$\mathrm{X}$} \\
\hline & Relative importance & SD & Rank & relative importance & SD & Rank & & \\
\hline & index(Rii) & OF & & index(RII)1 & OF & & & \\
\hline & & RII & & & RII & & & \\
\hline Location & 3.62 & 0.75 & 1 & 3.19 & 1.06 & 7 & 1.00 & 6.00 \\
\hline Size of plot & 3.54 & 0.81 & 2 & 2.27 & 0.96 & 13 & 0.30 & 1.80 \\
\hline State of repair & 3.38 & 0.98 & 3 & 3.08 & 1.06 & 9 & 1.00 & 6.00 \\
\hline Age & 3.35 & 0.94 & 4 & 2.35 & 1.09 & 12 & 0.03 & 0.16 \\
\hline Water & 3.15 & 1.00 & 5 & 3.38 & 0.98 & 4 & 1.00 & 6.00 \\
\hline Electricity & 3.08 & 1.06 & 6 & 3.46 & 0.95 & 3 & 0.97 & 5.84 \\
\hline Finishes & 2.92 & 1.06 & 7 & 2.73 & 1.00 & 11 & 0.70 & 4.20 \\
\hline $\begin{array}{l}\text { Number of } \\
\text { bedroom }\end{array}$ & 2.88 & 0.99 & 8 & 3.19 & 1.06 & 7 & 0.66 & 3.95 \\
\hline Size of room & 2.15 & 1.08 & 9 & 3.23 & 0.99 & 6 & 0.00 & 0.00 \\
\hline Security & 2.08 & 1.20 & 10 & 3.69 & 0.74 & 1 & 0.25 & 1.50 \\
\hline $\begin{array}{l}\text { Number of } \\
\text { toilet/bath3.54 }\end{array}$ & 1.96 & 0.99 & 11 & 2.81 & 0.93 & 10 & 0.30 & 1.8 \\
\hline Nearness to work & 1.81 & 0.88 & 12 & 3.54 & 0.81 & 2 & 0.00 & 0.00 \\
\hline Parking space & 1.62 & 0.9 & 13 & 3.38 & 0.90 & 4 & 0.00 & 0.00 \\
\hline Telephone & 1.54 & 0.95 & 14 & 1.75 & 0.92 & 14 & 1.00 & 6.00 \\
\hline
\end{tabular}

Source: analysis of surveyed data, 2006

Table 2: Ranking of salient variables by buyers and valuers of duplex

\begin{tabular}{|c|c|c|c|c|c|c|c|c|}
\hline \multirow[t]{2}{*}{ Variables } & \multicolumn{3}{|l|}{ Vluers ratings } & \multicolumn{3}{|l|}{ Buyers ratings } & \multirow[t]{2}{*}{$\mathrm{W}$} & \multirow[t]{2}{*}{$\mathrm{X}$} \\
\hline & $\begin{array}{l}\text { relative importance } \\
\text { index(RII) }\end{array}$ & $\begin{array}{l}\text { SD } \\
\text { OF } \\
\text { RII }\end{array}$ & Rank & $\begin{array}{l}\text { Relative importance } \\
\text { index(Rii) }\end{array}$ & $\begin{array}{l}\text { SD } \\
\text { OF } \\
\text { RII }\end{array}$ & Rank & & \\
\hline Location & 3.73 & 0.72 & 1 & 3.77 & 0.59 & 1 & 0.92 & 5.50 \\
\hline Security & 3.69 & 0.84 & 2 & 1.88 & 0.99 & 13 & 0.03 & 0.16 \\
\hline Size of plot & 3.62 & 0.90 & 3 & 3.88 & 0.90 & 6 & 0.82 & 4.90 \\
\hline State of repairs & 3.38 & 0.98 & 4 & 3.46 & 0.95 & 4 & 0.97 & 5.84 \\
\hline Age & 3.23 & 0.81 & 5 & 2.12 & 1.03 & 11 & 0.00 & 0.00 \\
\hline Number of bedroom & 3.19 & 1.06 & 6 & 3.00 & 1.10 & 8 & 0.97 & 5.84 \\
\hline Size of room & 3.08 & 1.06 & 7 & 3.12 & 1.03 & 7 & 0.97 & 5.84 \\
\hline Electricity & 3.00 & 1.10 & 8 & 3.69 & 0.74 & 2 & 0.97 & 5.84 \\
\hline Number of toilet/bath & 2.92 & 1.06 & 9 & 2.88 & 0.99 & 9 & 0.90 & 5.40 \\
\hline Nearness to work & 1.92 & 0.97 & 10 & 1.42 & 0.81 & 14 & 1.00 & 6.00 \\
\hline Water & 1.54 & 0.95 & 11 & 3.65 & 0.80 & 3 & 0.08 & 0.50 \\
\hline Finishes & 1.38 & 0.80 & 12 & 3.46 & 0.95 & 4 & 0.03 & 0.16 \\
\hline Parking space & 1.34 & 0.80 & 13 & 2.08 & 1.06 & 12 & 0.66 & 3.95 \\
\hline Telephone & 1.27 & 0.72 & 14 & 2.15 & 1.12 & 10 & 0.92 & 5.50 \\
\hline
\end{tabular}

Source: analysis of surveyed data, 2006

Table 3: Parameter estimation of the multiple regression analysis of residential property values for bock of flats

\begin{tabular}{lrcccc}
\hline Parameters & Coefficients & Standard error of B & Beta & t-value & Sig. F. \\
\hline $\mathrm{b}_{\mathrm{o}}$ & -27.422 & 10.816 & - & -2.435 & 0.015 \\
$\mathrm{~b}_{2}$ & 2.385 & 0.660 & 0.480 & 3.615 & 0.001 \\
$\mathrm{~b}_{3}$ & 13.340 & 5.307 & 0.328 & 2.514 & 0.016 \\
$\mathrm{~b}_{4}$ & 18.031 & 6.595 & 0.408 & 2.734 & 0.007 \\
$\mathrm{~b}_{5}$ & 0.353 & 0.323 & -0.161 & -1.694 & 0.280 \\
\hline
\end{tabular}

$\mathrm{R} 2=0.344 \quad \mathrm{~F}-$ value 5.375

The lead model is therefore as shown below

$\mathrm{Y}=-27.422+2.385 \mathrm{X}_{2}+13.340 \mathrm{X}_{3} \quad+18.031 \mathrm{X}_{4}-0.353 \mathrm{X}_{5}$

Where $\mathrm{Y}=$ Actual price paid for the properties; $\mathrm{X}_{2}=$ Regularity of electricity; $\mathrm{X}_{3}=$ nearness to work; $100 ; \mathrm{X}_{4}=$ security of neighborhood; $\mathrm{X}_{5}=$

Age of buildings

Size of plots, number of toilets/baths and regularity of electricity are areas where partial and high level of agreement exists between buyers and valuers. With age of the buildings, there is no level of agreement between the buyers and the valuers.

With respect to the total effects of the combined variables, Kendall's coefficient of concordance W reveals that there is a partial and high level of agreement between the rankings of buyers and valuers for duplex $(\mathrm{W}=0.61)$ and partial but low level of agreement for block of flats( $\mathrm{W}=0.39)$. Figure 1 illustrates this. The areas under the curve show the dispersion between the rankings of the valuers and the buyers. This is bigger for block of flats signifying a higher level of disagreement. 
Am. J. Applied Sci., 4 (10): 774-778, 2007

Table 4: Comparing buyers and valuers ranking with regression results (block of flats)

\begin{tabular}{lcc}
\hline Variables & Valuers ranking & buyers ranking \\
\hline Regularity of electricity $\mathrm{X}_{2}$ & 6 & 3 \\
Nearness to work $\mathrm{X}_{3}$ & 12 & 2 \\
Security of neighborhood $\mathrm{X}_{4}$ & 10 & 1 \\
Age of buildings $\mathrm{X}_{5}$ & 4 & 12 \\
\hline
\end{tabular}

Table 5: Parameter estimation of the multiple regression analysis of residential property values for duplex

\begin{tabular}{lccccc}
\hline Parameters & Coefficients & Standard error & Beta & t-value & Sigf. \\
\hline Bo & -63.356 & 14.884 & - & -4.257 & 0.002 \\
$\mathrm{~b}_{1}$ & 2.016 & 1.727 & 0.171 & 1.167 & 0.237 \\
$\mathrm{~b}_{2}$ & 2.242 & 0.744 & 0.485 & 3.014 & 0.015 \\
$\mathrm{~b}_{4}$ & 23.503 & 8.472 & 0.500 & 2.774 & 0.022 \\
$\mathrm{~b}_{5}$ & 0.495 & 0.292 & 0.283 & 1.696 & 0.124 \\
$\mathrm{~b}_{6}$ & 0.003568 & 0.010 & 0.552 & 3.652 & 0.005 \\
\hline
\end{tabular}

$\mathrm{R}^{2}=0.827 \quad$ F-value 8.611

The lead model is therefore as shown below:

$\mathrm{Y}=-63.356+2.016 \mathrm{X}_{1}+2.242 \mathrm{X}_{2}+23.503 \mathrm{X}_{4} 0.495 \mathrm{X}_{5}+0.003568 \mathrm{X}_{6}$

where

$\mathrm{X}_{1}=$ Location; $\mathrm{X}_{2}=$ Regularity of electricity; $\mathrm{X}_{4}=$ Security of neighbourhood; $\mathrm{X}_{5}=$ Age of building; $\mathrm{X}_{6}=$ Size of plot

Table 6: Comparing buyers and valuers ranking with regression results (duplex)

\begin{tabular}{lcc}
\hline Variables & Valuers ranking & Buyers ranking \\
\hline Location $\mathrm{X}_{1}$ & 1 & 1 \\
Electricity $\mathrm{X}_{2}$ & 8 & 2 \\
Security of neighbourhood $\mathrm{X}_{4}$ & 2 & 13 \\
Age of building $\mathrm{X}_{5}$ & 5 & 11 \\
Size of plot $\mathrm{X}_{6}$ & 3 & 6 \\
\hline
\end{tabular}

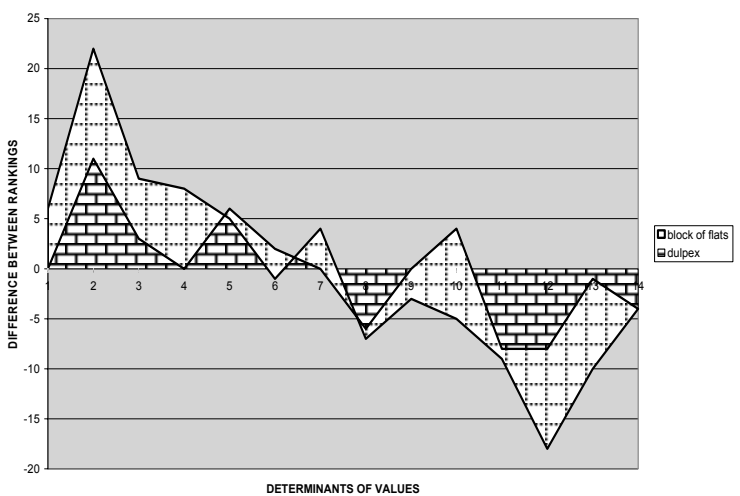

Fig. 1: Dispersion of the rankings of the buyers from the valuers

The test statistic $\mathrm{X}$ at 0.05 levels of significance reveals that there is no significant level of agreement between the buyers and the valuers for both duplex and block of flats. The issue here is whether or not the buyers' preferences as reflected in the market are correctly interpreted by the valuers. To be able to verify these, the actual price paid for these properties were regressed against their attributes (the identified variables).

Using stepwise method with probability of $\mathrm{F}$ - to enter of 0.8 and F- to remove of 1.0, ten models were obtained for the block of flats. The results of the estimated parameters for the lead model are shown in Table 3.

With the exception of the age of the buildings, all the variables are statistically significant. Comparing these with the valuers and buyers rankings for the block of flats, we found that while buyers rank 3 out 4 of these variables among the top fives, only 1 of the first top of the valuers could make the list (Table 4).

Also, a step wise regression analysis performed on the variables in respect of duplex produced nine ${ }^{[9]}$ models and the lead model out of these has the parameters estimate as shown in Table 5 .

The performance of the overall equation is good as indicated by $\mathrm{R}^{2}(0.827)$ statistic and F-value (8.611). All the variables with the exception of location and age of building are statistically significant at 0.05 levels. Table 6 shows a comparison of buyers and valuers ranking with the regression results.

There is a better agreement between valuers and buyers ranking when compared with the regression results. For Valuers, 4 out of the top 6 variables made the regression list while buyers' 3 out of top 6 made the same list. This confirms the relatively high level of agreement found among valuers and buyers in respect of duplex $(\mathrm{w}=0.61)$

The difference between the perceptions of the buyers of block of flats and that of duplex is not unexpected. In Nigeria, residential properties are broadly classified into tenement buildings for low 
income, block of flats for middle income and duplex / detached houses for the high-income earner. These categories of users have different socio-economic backgrounds, which will invariably affect their taste and value judgments. The valuers are however trained and are expected to know how the socio-economic background of different groups will translate into their demand and hence the economic worth of the property. The issue here is how effective are the valuers doing this?

From the results, there are sufficient evidence that the valuers may not be interpreting the market correctly in respect of both the duplex and block of flats. While the valuers lay emphasis on the traditional attributes of property that are believed to determine values (e.g. location, age of building and state of repairs), the buyers emphasis here is on those attributes that impinge directly on their welfare such as security of neihgbourhood, nearness to place of works and regularity of electricity supply.

\section{CONCLUSION}

The study has revealed that the methods of valuation of Nigerian estate surveyors and valuers do not take into consideration the buyers preferences in the assessments of residential property value. The extent of valuation variance among these practitioners to some extent may be adduced to this shortcoming ${ }^{[9,14]}$. The danger here is that clients may be disillusioned when valuation prepared by one valuer is greatly at variance with the one prepared by another giving the same set of information or the value estimated is not supported by market transaction.

In this wise, therefore the estate surveyors and valuers and the professional institution must, as matter of urgency, do something to improve the quality of services they render in this area. In this regard, the Nigerian Institution of Estate Surveyors and Valuers is urged to evolve policies that will encourage the development and discussion of ideas, opinions and issues related to the process of enhancing both the theoretical and practical knowledge in residential property valuation. The Continuous Professional Development (CPD) programme of the institution should be refocused to address this area of deficiency.

\section{REFERENCES}

1. Mackmin, D., 1985. Is there a residential valuer in the house? J. Valuation, 3: 384-90.
2. Adair, A.S., J.N. Berry and W.S. McGreal, 1996. Valuation of residential property: Analysis of participant behavior. J. Property Valuation and Investment, 14: 20-35.

3. Grisson, T.A., 1991. Valuation without comparables. The Appraisal J., 59: 370-6.

4. Greaves, M., 1984. The determinants of residential values: The hierarchical and Statistical approaches. J. Valuation, 3: 5-23.

5. Wyatt, P., 1996. The development of a property information system (GIS). J. Property Res., 13: 317-36.

6. Daly, J., S. Gronow and F. Plimmer, 2003. Consumer behavior in the valuation of residential property: A comparative study in the United Kingdom, Ireland and Australia. J. Property Management, 21: 295-314.

7. Lewis, O., 1999. The use of artificial intelligence techniques to assist in the valuation of residential properties. Ph.D. Thesis, University of Glamorgan, Pontypridd.

8. Ajayi, C.A., 1997. Towards new directions for property valuation in Nigeria. The Estate Surveyor and Valuer. J. Nigerian Institution of Estate Surveyors and Valuers, 20: 20-27.

9. Ogunba, O.A., 1997. A study of valuation and pricing practices in the residential property market in Lagos Metropolis. M. Sc. Thesis, Obafemi Awolowo University, Ile Ife, Nigeria.

10. Bible, D.S. and L.A. Brown, 1981. Place utility, attribute tradeoff and choice behavior in an intraurban migration context. Social- Economic Planning Sci., 15: 37-44.

11. Munro, M. and D. Lamont, 1985. Neigbourhood perception, preferences and household mobility in the Glasgow private housing market. Environment and Planning A, 17: 1331-50.

12. Churchchill, G.A., 1991. Marketing Research: Methodological Foundations. 5th Edn., Dryden Press, New York.

13. Earl, K.B. and K.S. Martins, 1982. Basic Statistics for Business and Economics. McGraw Hill Inc, New York.

14. Ajayi, C.A., 2006. Towards New Direction for Property Valuation Paradigm. I. AOkewole, S. A. Daramola, C.A. Ajayi, O. A. Ogunba and K. T. Odusami (Eds.). The Built Environment: Innovation Policy and Sustainable Development, Covenant University Otta, Ogun State, Nigeria. 